\title{
ALGUNAS CONTRIBUCIONES AL CATÁLOGO DEL PINTOR BALDOMERO ROMERO RESSENDI
}

\section{SOME CONTRIBUTIONS TO THE CATALOGUE OF THE PAINTER BALDOMERO ROMERO RESSENDI}

\author{
Álvaro Cabezas García \\ Grupo de investigación HUM317: LARAÑA. España \\ ORCID: 0000-0001-9675-8964 \\ alvarocabezasgarcia@gmail.com
}

Se aportan en este estudio un total de ocho pinturas inéditas firmadas por Baldomero Romero Ressendi. Todas se conservan en colecciones particulares de Sevilla y suponen, en su variedad temática, nuevas versiones de géneros bien conocidos y recurrentes en la producción del artista, como fueron, concretamente, el religioso y el circense. Ressendi fue un artista de gran maestría pero anacrónico $\mathrm{y}$, por tanto, falto de un claro compromiso vanguardista si se inscribe en el contexto del arte español de la segunda mitad del siglo XX. A pesar de ello, la extravagancia que caracterizó su obra provocó filias y fobias por igual: animadversión entre los círculos académicos y aprecio de importantes promotores que le procuraron multitud de encargos hasta el final de sus días. A continuación, podrán conocerse algunos de los que no habían sido publicados hasta ahora.

Palabras clave: pintura; Romero Ressendi; siglo XX; Sevilla; Madrid.

A total of eight unreleased paintings signed by Baldomero Romero Ressendi are provided in this studio. All are preserved in particular collections of Seville and assume, in their thematic variety, new versions of well-known and recurring genres in the artist's production, such as, religious and circus themes. Ressendi was an artist of great mastery but anachronistic and therefore lacking a clear avant-garde commitment if his work is analizaged in the context of art Spanish of the second half of the twentieth century. Despite this, the extravagance that characterized his work provoked philias and phobias: animadversion among academic circles and appreciation of important promoters who sought him many commissions until the end of his days. Below you will find out some of those that had not been published until now.

Keywords: painting; Romero Ressendi; $20^{\text {th }}$ century; Seville; Madrid. 
No resulta nada infrecuente que periódicamente aparezcan en el mercado artístico español obras hasta ahora desconocidas del pintor Baldomero Romero Ressendi (Sevilla, 20 de enero de 1922 - Madrid, 11 de abril de 1977) ${ }^{1}$. Esto se debe principalmente a que este autor ha recibido poca atención por parte de la historiografía ${ }^{2}$. Como consecuencia de ello, muchas pinturas -incluso series completas-, han quedado fuera de los registros publicados, sobre todo por el hecho de conservarse en domicilios particulares y en manos de propietarios que las publicitan para la venta en casas de subastas en función de sus propias necesidades de ganancia económica. El escaso conjunto de estudios que existen sobre el artista es inversamente proporcional a lo prolijo de su producción. Por consiguiente, parece lógico advertir muchas lagunas en su catálogo pictórico, que resulta pertinente colmar con el tiempo y el descubrimiento de nuevas obras como las que integran el grupo que aquí se expone y estudia por primera vez, conservado en dos colecciones particulares sevillanas.

1 Tan solo en el último año han aparecido no menos de una docena de pinturas firmadas por él y puestas en venta en las siguientes casas de subastas: Ansorena (subasta de 3 de diciembre de 2019, lote 845: Figuras en penumbra. 1970. Óleo sobre tabla, 37 x $47 \mathrm{~cm}$ ); Ansorena (subasta de marzo de 2020, lote 129: Tres niños payasos. Óleo sobre tabla, $44 \mathrm{x}$ $36,5 \mathrm{~cm}$ ); Isbylia (subasta de 10 de marzo de 2020, lote 661: Retrato de señora. Óleo sobre lienzo, 61 x $50 \mathrm{~cm}$ ); Segre (subasta de 24 de marzo de 2020, lote 203: Bodegón de liebre. Óleo sobre lienzo, 53 x 63,5 cm); Segre (subasta de 24 de marzo de 2020, lote 186: Paisaje. Óleo sobre lienzo, 85 x $58 \mathrm{~cm}$. 1943); Isbylia (subasta de junio de 2020, lote 750: Bodegón. Óleo sobre lienzo, 97,5 x $78 \mathrm{~cm}$ ); Abalarte (subasta de julio de 2020, lote 1.138: Martirio de San Sebastián. 1967. Óleo sobre lienzo, 130 x $88 \mathrm{~cm}$ ); Ansorena (subasta de 30 de septiembre de 2020, lote 145: Encapuchado. Óleo sobre lienzo, 61 x $50 \mathrm{~cm}$ ); Isbylia (subasta de octubre de 2020, lote 536: Retrato femenino. Óleo sobre lienzo, 61,5 x $50 \mathrm{~cm}$ ); Isbylia (subasta de octubre de 2020, lote 618: Máscara. Óleo sobre tabla, 23 x $32 \mathrm{~cm}$ ); Ansorena (subasta de noviembre de 2020, lote 118: Gatoltorero. Óleo sobre lienzo, 61 x $50 \mathrm{~cm}$ ); Ansorena (subasta de noviembre de 2020, lote 119: Gatalmaja. Óleo sobre lienzo, 61 x $50 \mathrm{~cm}$ ); Segre (subasta de 16 de febrero de 2021, lote 267: Máscara de carnaval. 1973. Óleo sobre táblex, 46 x $38 \mathrm{~cm}$ ); Isbylia (subasta de febrero de 2021, lote 515: Saltando a la piola. Óleo sobre lienzo, 50 x $61 \mathrm{~cm}$ ); Isbylia (subasta de febrero de 2021, lote 535: Arlequín. Óleo sobre lienzo, 61 x $50 \mathrm{~cm}$ ); Isbylia (subasta de febrero de 2021, lote 565: Personajes femeninos. Óleo sobre lienzo, 50 x $61 \mathrm{~cm}$ ); Isbylia (subasta de febrero de 2021, lote 671: Pareja de personajes goyescos. Óleo sobre lienzo, 40 x $30 \mathrm{~cm}$ ); Isbylia (subasta de febrero de 2021, lote 674: Escena goyesca. Óleo sobre lienzo, 50 x $60 \mathrm{~cm}$ ); Isbylia (subasta de febrero de 2021, lote 675: Escena goyesca. Óleo sobre lienzo, 50 x $60 \mathrm{~cm}$ ); y Alcalá (subasta de marzo de 2021, lote 410: Toreros. Óleo sobre lienzo, 51 x $41 \mathrm{~cm}$ ).

${ }^{2}$ Los estudios y referencias sobre Ressendi son los de AAVV., 1979: 2.892. Medianero Hernández, 1984: 369. AAVV., 1990. De la Banda, 1994: 423. Fernández Lacomba, 1995. Valdivieso, 1986 (2002): 495-497. Covelo López, 2000. 
Ressendi ${ }^{3}$ vivió cincuenta y cinco años ${ }^{4}$, pero desarrolló una intensa carrera de más de tres décadas de duración en la que alcanzó con sobresaliente altas cotas de calidad entre los críticos y de confianza y respaldo por parte de un público fiel que se agrupaba entre Sevilla, el litoral gaditano y Madrid ${ }^{5}$. La base sobre la que floreció su éxito estaba compuesta por una sólida formación teórica y práctica y por un valiente y expresivo estilo pictórico que supuso un revulsivo estético, aislado pero muy destacable, en el contexto histórico en que vivió. Presumiblemente puede razonarse que tras ahondar profundamente -también en el plano teórico-, en el estudio de la pintura universal, el artista se auxilió de las soluciones adoptadas por autores de su predilección para avanzar sobre las mismas ${ }^{6} \mathrm{y}$, con el correr de los años, lograr arribar en un estadio en el que se enseñoreó artísticamente, no solo en el apartado técnico -absolutamente irreprochable-, sino en el del reconocimiento y la aceptación estética de su particular e irrepetible estilo, tanto entre los entendidos como para el gran público que lo promocionó y valoró.

Llegar a esa consagración artística le supuso recorrer un arduo camino durante años de estudio y laborioso esfuerzo desde sus primeros acercamientos a la pintura, siendo tan solo un adolescente, hasta cursar, entre 1937 y 1938, las disciplinas fundamentales -sobre todo dibujo-, en la antigua Escuela sevillana de Artes y Oficios, ubicada entonces en la Plaza de España ${ }^{7}$. En palabras de José Hernández Díaz (Sevilla, 1906 - 1998), Ressendi debió aprovechar fecundamente aquellas

${ }^{3}$ El artista potenció el uso de su apellido materno como símbolo distintivo de su quehacer, casi como si de una marca comercial se tratara. Así firmó como "R. Ressendi" a partir de 1948. Antes de esa fecha lo hacía como "Romero Ressendi", véase Covelo López, 2000: 75.

4 Algunos datos biográficos han sido facilitados por su hermana Romero Contreras, 1990: s/p. Por ella se sabe que Ressendi nació en el $n^{\circ} 3$ de la calle Rivero de Sevilla y que no asistió al colegio hasta haber cumplido los once años, en 1933, estando su formación hasta entonces al cuidado exclusivo de su madre, una mexicana de Querétaro, llamada Mercedes Contreras Chinchón Ressendi.

${ }^{5}$ Fuera de los encargos particulares solo pueden considerarse como de cierta oficialidad el frustrado proyecto de adorno del interior de la abadía de la Santa Cruz del Valle de los Caídos - para el que Ressendi solo alcanzó a realizar los bocetos, véase Valdivieso, 1986 (2002): 495-; el retrato inacabado del general Franco, véase Fernández Lacomba, 1995: 18-24; y la serie de cinco pinturas pasionistas que ejecutó en 1959 para la iglesia del Pilar de Madrid, véase Covelo López, 2000: 166-175.

${ }^{6}$ Esta consideración es compartida por Covelo López, 2000, 40: "Ressendi exploró la propia trayectoria de la pintura andaluza (sevillana por más señas), retomando el camino interrumpido en el último barroco".

7 Romero Contreras, 1990: s/p. asegura que, con anterioridad, ya había expuesto, por consejo del pintor Francisco Hohenleiter de Castro (Cádiz, 1889 - Sevilla, 1968), en la Exposición de primavera de 1936, con tan solo catorce años, Dos cabezas, Un retrato de su hermana y Un autorretrato. A pesar de estos iniciales experimentos, por satisfacer la insistencia de su padre, Baldomero Romero Escacena -que ejercía como médico en Sanlúcar de 
primeras experiencias a tenor de los conocimientos y las dotes con que llegó a la Escuela Superior de Bellas Artes en 1941, donde el citado profesor -que se estrenaba en esa plaza después de haber conseguido el traslado desde la de Bellas Artes de San Carlos de Valencia $-^{8}$, advirtió una calidad que brillaba por su agudeza y una encomiable comprensión del saber humanístico, hasta el punto de tomarlo rápidamente como discípulo personal y disfrutar de una relación plena de cordialidad y afecto ${ }^{9}$. Tanta fue la consideración que el joven alumno despertó en el catedrático de Historia del Arte que este llegó a ofrecerle ocupar su lugar cuando aquel volvió a Sevilla en 1946 tras completar su formación con una estancia en la Academia de Bellas Artes de San Fernando de Madrid, que aprovechó para estudiar grabado ${ }^{10}$. Sin embargo, debido a su marcado carácter fogoso ${ }^{11}$, rechazó la propuesta que, de ser aceptada, le hubiese procurado una permanente estabilidad laboral ${ }^{12}$, emprendiendo, en cambio, el difícil camino del ejercicio de la pintura independiente.

A ella se consagró, con fama y viva polémica, en ese mismo año al participar en una exposición cuyos efectos fijarían su apellido y su capacidad artística.

Barrameda-, inició los estudios de medicina y trabajó temporalmente en una casa de Socorro, véase Covelo López, 2000: 15.

${ }^{8}$ González, 1998: 15. De hecho, Ressendi había seguido exponiendo dibujos y algunos lienzos entre 1940 y 1941 en la Galería Aeolian de Madrid, véase Romero Contreras, 1990: s/p.

9 Habría que considerar que Ressendi perteneció a una de las primeras tandas de alumnos de las muchas a las que enseñó Hernández Díaz a lo largo de su carrera y los inicios suelen resultar significativos y decisivos, también en el plano académico. Además Ressendi llamaba la atención por "rezumar originalidad creativa, una imaginación desbordante y desbordada y unas interesantes reacciones ante el modelo", valores que, a ojos del profesor, sobresalían por encima de los de sus compañeros en técnica, composición, riqueza cromática de su paleta y, también, por las versiones tan personales que hacía de los temas propuestos, véase Hernández Díaz, 1990: s/p. Algunos de los compañeros que tuvo Ressendi en aquella institución entre 1941 y 1943, fueron los prácticamente desconocidos L. Segura (matriculado en la citada institución en 1940) y L. Talavera (en 1941), algunas de cuyas obras se han identificado en los fondos del patrimonio artístico de la Universidad de Sevilla, véase

$\mathrm{http}: / / \mathrm{www}$. patrimonioartistico.us.es/autor.jsp.?id $=381 \&$ tipo $=\mathrm{v} \&$ buscando $=$ true $\& \mathrm{r}$ epetir $=$ true\&order_method $=$ desc $\& n p=0 \&$ orderby $=$ nombre_autor\&repetir $=$ true $\&$ grup $\mathrm{o}=13 \&$ buscando=true\&campo=grupo\&num_regs_pag=20), (consultado el 10-10-2020). También fue compañero de Antonio Bolaños, véase ABC de Sevilla, 27-8-2016: 13.

${ }^{10}$ Coincide esa oferta realizada a Ressendi con la designación de Hernández Díaz como encargado de la cátedra vacante de Fundamentos e Historia de los Sistemas Filosóficos de la entones Facultad de Filosofía y Letras, circunstancia que le permitió dejar la docencia en la Escuela Superior de Bellas Artes, aunque conservara sus funciones directivas en esta institución, véase González, 1998: 15.

${ }_{11}$ Así lo define Medianero Hernández, 1984: 369.

12 Romero Contreras, 1990: s/p. 
El fotógrafo Antonio Cubiles López había abierto su estudio en la, por entonces, sevillana avenida de José Antonio en 1944 y dos años más tarde organizó allí una muestra en la que Ressendi exhibió el lienzo de Las tentaciones de San Jerónimo, cuya lectura iconográfica enardeció los ánimos del cardenal Pedro Segura (Carazo, 1880 - Madrid, 1957), que llegó a plantearse excomulgar al pintor como castigo por su atrevimiento ${ }^{13}$. Sin embargo, esta pretensión pudo evitarse gracias a la actuación de su valedor Hernández Díaz - persona de referencia para la dignidad eclesiástica en cuestiones artísticas-, que fue apremiado a emitir un informe sobre la "obscenidad" que creía el prelado caracterizaba la obra, algo que al catedrático "nunca se lo pareció"14, por lo que libró así a Ressendi, con su autoridad, de padecer el grave perjuicio que tal consideración pudiera provocar en la compleja coyuntura histórica de esos años.

Esos apoyos fueron volviéndose cada vez más numerosos e importantes con el paso del tiempo y la ejecución de nuevas pinturas. Además de Hernández Díaz en el plano teórico y Hohenleiter en el práctico, uno de los primeros promotores de su obra fue el torero Manuel Mejías Rapela "Bienvenida" (Bienvenida, 1884 Madrid, 1964), que le encargó en Madrid sendos retratos de él (El Papa Negro), y de su hijo Antonio Mejías Jiménez "Bienvenida" (Caracas, 1922 - Madrid, 1975) en $1948^{15}$. Esta conexión le abrió las puertas del mundo taurino, cuyos integrantes le procuraron mucho trabajo desde entonces ${ }^{16}$. Si ese mecenazgo sirvió a Ressendi para integrarse en un ambiente idóneo a su carácter bohemio ${ }^{17}$, el de otro de sus más importantes benefactores le sirvió para entrar en contacto con los más conspicuos círculos del régimen franquista: el general José Rodríguez Díaz de Lecea (Matanzas, Cuba, 1894 - Madrid, 1967) -un aviador que combatió en el ejército

${ }^{13}$ Covelo López, 2000: 23 y 24. La opinión del cardenal sí fue ratificada por el historiador del arte Antonio Sancho Corbacho (Sevilla, 1909 - 1982), véase ABC de Sevilla, 17-2-1982: 29.

${ }^{14}$ A pesar de la larga e impenitente devoción que Hernández Díaz profesaba por Ressendi, aporta un testimonio en que se queja con cierta amargura de que cuando se encontraba con él en las exposiciones en las que participaba, tanto en Sevilla como en Madrid, siempre le aconsejaba con lealtad, y aunque Ressendi admitía todos esos consejos momentáneamente, no lo hacía con "verdadero propósito de aprovechar sus valiosas condiciones”, véase Hernández Díaz, 1990: s/p.

${ }^{15}$ Covelo López, 2000: 15, 75 y 77.

${ }^{16}$ Esta temática llegó incluso a obsesionarle. De las muchas pinturas que dedicó al género merecen destacarse Gato/torero (subastada en Ansorena en noviembre de 2020 como lote 118), Perroltorero, Arlequín torero, Autorretrato con capote, Autorretrato con traje de luces, Aprendiz de torero, Torero fumando, Esperando en la puerta de toriles (dedicada a Antonio Bienvenida), Pase por alto, El pavo o el inquietante Encapuchado con montera. Muchas de ellas fueron reproducidas por Covelo López, 2000: 143-152.

${ }^{17}$ El carácter de Ressendi ha sido muy bien descrito por una hija, Paloma Vosselle, entrevistada por Alfredo Valenzuela en $A B C, 27-5-2007: 30$. 
sublevado durante la guerra y acabó siendo ministro del Aire (1957-1962) y del Ejército interinamente (en mayo de 1962). Comenzó encargándole un retrato ambientado y henchido de fuerza y determinación ${ }^{18}$, siguió con otros para familiares, le puso taller en su propia casa de Madrid (donde trabajó entre 1949 y 1951), y acabó por presentarlo ante Franco procurándole consiguiera retratarle y contraer el compromiso de decorar, además, la basílica del Valle de los Caídos. Estos últimos proyectos, como se ha indicado anteriormente, no fueron ejecutados a la postre ${ }^{19}$, pero estas conexiones le sirvieron para disfrutar de sustento, fama y consideración artística ${ }^{20}$.

En Sevilla todos estos éxitos le habían permitido abrir un estudio en la avenida de José Antonio ${ }^{21}$, donde trabajó hasta que, tras volver de Madrid en 1951 decidió establecerse en Alcalá de Guadaira, localidad donde levantó la finca El Zacatín imponiendo su criterio artístico al del constructor Daniel Álvarez, a orillas del río que da nombre a la población y situada junto a la estación de Adufe ${ }^{22}$. En 1956 realizó una estancia de seis meses en París y, con posterioridad, algunos periodos cortos en Málaga ${ }^{23}$.

Algunos años después y valorando que muchos encargos provenían de Madrid, se estableció en la capital en 1964, primero en la calle Maldonado y luego en Juan Ramón Jiménez. Además de pintar mucho y con gran velocidad para encargos particulares, quizá con un estilo de factura más fácil y alejado del que había practicado en Sevilla, también participó y vendió en exposiciones organizadas

${ }_{18}$ Reproducido por Covelo López, 2000: 92.

19 Fernández Lacomba, 1995: 18-24 cree que Ressendi no quería ser etiquetado como "artista del régimen", pero sospecha que hubo razones más prosaicas, relacionadas con la incómoda seguridad mantenida en El Pardo, que impidieron al pintor ejecutar esos encargos.

${ }^{20}$ De la Banda, 1994: 423 señala esta consideración en Madrid. Otros importantes personajes, de los muchos que retrató por estos años, fueron Luis Alarcón de la Lastra (Sevilla, 1891 - 1971), aristócrata y exministro de Franco, María Josefa Sánchez-Dalp y Leguina, marquesa viuda de Saltillo (Sevilla, 1928 - 2018), el empresario Ángel Casal Casado (E1 Ferrol, 1901 - Sevilla, 1983), o el rejoneador Salvador Guardiola Domínguez (Sevilla, 1927 - Palma de Mallorca, 1960).

${ }^{21}$ Aquí le frecuentó mucho el periodista Manuel Barrios Gutiérrez (San Fernando, 1924 - Sevilla, 2012), que cultivó cierta amistad con Ressendi y que fijó el recuerdo que tenía de él en un artículo en que reseñaba la urgencia con la que acometía la ejecución de su pintura -realizaba lienzos de pequeño tamaño con una rapidez asombrosa: a veces no superaba los veinte minutos de ejecución-, y con la que se enfrentaba a la vida como si fuera el mejor exponente contemporáneo del tempus fugit del Barroco. Lo recoge Covelo López, 2000: 28.

22 En Alcalá de Guadaira encontró un ambiente más bien hostil, véase Covelo López, 2000: 23, pero la tradición local considera que se le mantenía un enorme respeto llegando incluso hasta la veneración. Allí recurrió con frecuencia a los mismos modelos para sus cuadros: Frascuelo, Francisco y Pachocha.

${ }^{23}$ Covelo López, 2000: 49. 
por las galerías Fortuny y Durán en $1969^{24}$. Precisamente en este sector encontró un firme apoyo en Antonio Manuel Campoy (Cuevas de Almanzora, 1924 - Madrid, 1993), un galerista de Heller y crítico activo en varios medios de comunicación que tenía una conexión sevillana como académico de Santa Isabel de Hungría $^{25}$. Conoció bien a Ressendi y lo relacionó de manera provechosa para su adelantamiento artístico y comercial y, ulteriormente, recogió en un pequeño texto una alabanza superlativa salpicada de anécdotas y memorias sobre él que tendían a clasificarlo como un pintor maldito e incomprendido ${ }^{26}$.

Esta consideración se antoja equívoca al analizar sus pinturas con mayor profundidad. Siempre se diferenciaban por una técnica perfecta ${ }^{27}$ que permitía la solvente práctica de varios registros estéticos en función, por un lado, de la pincelada - a veces muy suelta y libre hasta la apariencia de conformar piezas inacabadas, otras, a conveniencia, realista, rigurosa, limpia y analítica como si de una fotografía se tratara-, y, por otro, de una temática diversa y variada: desde la representación de personajes grotescos ${ }^{28}$ Ressendi viajó hasta una aparentemente incierta religiosidad ${ }^{29}$, pasando por géneros tan dispares como el paisaje, el orientalismo, la tauromaquia ${ }^{30}$, el retrato ${ }^{31}$, el bodegón ${ }^{32}$, las escenas circenses ${ }^{33}$, las de metamorfosis $^{34}$, las literarias o la interesante revisión del folclorismo que propuso

${ }^{24}$ Murió allí tras algunas complicaciones cardiacas, véase Covelo López, 2000: 27 y 28.

${ }^{25}$ Gozaba, además, de la amistad y el favor de quien ejerciera como director general de Bellas Artes entre 1968 y 1974, Florentino Pérez-Embid (Aracena, 1918 - Madrid, 1974), véase Campoy, 1977.

${ }^{26}$ Campoy, 1990: s/p.

${ }^{27}$ Hacía recaer la idea de sus composiciones sobre la sólida base del dibujo, que manejaba a placer, con gran fuerza plástica e incansablemente. Es, posiblemente, lo que más apreciaba Hernández Díaz, 1990: s/p. de su trabajo.

${ }^{28}$ Covelo López, 2000: 143-152.

${ }^{29}$ Covelo López, 2000: 166-207.

${ }^{30}$ Covelo López, 2000: 143-152, en cualquier caso, estas obras están más próximas a la serie de la Tauromaquia de Francisco de Goya (Fuendetodos, 1746 - Burdeos, 1828), que a las tradicionales escenas costumbristas sevillanas del siglo XIX.

${ }^{31}$ Los hacía de dos tipos: los encargados por particulares, muy realistas aunque con un punto de arrebato en el trazo de los planos secundarios y los experimentales que plasmaba disfrazando a miembros de su servidumbre o, incluso, un viejo maniquí italiano. Esto hacía que presentaran, a veces, una falta de sinceridad, véase Covelo López, 2000: 49, 73-122 y 150 .

${ }^{32}$ En su más pura acepción de "naturalezas muertas" mostraba el vacío y la caducidad de los alimentos en las despensas de los más desfavorecidos, Covelo López, 2000: 57-72.

${ }^{33}$ Covelo López, 2000: 213-222.

${ }^{34}$ Covelo López, 2000: 209-212. 
con sus cuadros de gitanerías ${ }^{35}$ y "goyerías" 36 . Entre este surtido de posibilidades, los clientes de Ressendi podían adquirir tanto pinturas cuyos protagonistas simularan apariciones de cariz fantasmagórico y siniestro u otras donde los personajes no ofrecieran más que una latente ironía trágica. El atractivo de su pintura se encuentra en el perfecto equilibrio que consigue con la unión de contrarios: en lo terrenal de sus naturalezas muertas - de flores marchitas y frutos podridos representados hasta la obsesión del detalle-, también se encuentra un encomiable uso de la luz y la sombra donde a veces aquella se aprecia dorada y cálida y otras despersonalizada y eléctrica. Es posible por ello que sus comitentes, independientemente de su formación y gustos, no pudieran pasar sin tener una obra de Ressendi, no tanto por lo representado en ella, sino por la singular y poco convencional impronta que las distinguían. Es cierto que a veces se percibe horror en obras como El locutorio de San Bernardo o formas burlescas en Los borrachos, de tal manera que, como expresó Hernández Díaz su pintura supone "un golpetazo -favorable o no- al ánimo del espectador" ${ }^{37}$. Sin embargo, pocas veces resulta una pintura desagradable en lo visual, sino, más bien, extrañamente familiar, con reminiscencias tanto reales como oníricas.

Gracias a la versatilidad de su paleta los compradores de sus obras podían encuadrarse tanto en grupos de coleccionistas deseosos de desligarse del conservadurismo pictórico que imperaba en la Sevilla de posguerra como en el de los indagadores de aires creativos renovadores que coleccionando alguna obra de Ressendi conjuraban un espíritu revolucionario no perseguido explícitamente por el artista, pero que sí dimanaba del espíritu de su pintura. Algunos pertenecieron al mundo de la farándula y el toreo y otros eran integrantes del estamento militar que se situaba en la cúspide social del momento y que veían en el pintor -por sus dotes de retratista ágil aunque un tanto caprichoso ${ }^{38}$, la ocasión factible de conseguir una exaltación visual por parte de un elemento que quedaba al margen del encorsetado ambiente estético de posguerra y que

${ }^{35}$ Covelo López, 2000: 153-165. Ressendi describe aquí a la perfección el ambiente que tanto gustaba visitar: tablaos flamencos, patios de vecinos y fiestas populares, todo inmerso en un clima bastante oscuro, lleno de humo de tabaco y sudor. Paradójicamente para lo que resulta frecuente en el pintor, los rostros no expresan emociones, sino que más bien parecen caretas o máscaras.

36 Así las llamó el propio artista, por la clara dependencia de los modelos y soluciones tomadas de Goya, véase Covelo López, 2000: 130-142.

${ }^{37}$ Hernández Díaz, 1990: s/p.

${ }^{38}$ Solía ser desordenado con los horarios y anárquico en los plazos de entrega, véase Covelo López, 2000: 24. Además, “en los últimos años malgastó sus energías y en su pintura se aprecia un sentido de facilidad comercial en el que, sin embargo, se percibe la excepcional habilidad técnica", véase Valdivieso, 1986 (2002): 496. 
encarnaba las más reconocibles virtudes del artista contemporáneo ${ }^{39}$. Significaba, en última instancia, una transgresión contenida, extravagante para determinados círculos, pero no censurable en el plano estético o sociopolítico por su, también, latente anacronismo.

Esta aura no fue siempre la misma, pero es cierto que, desde su autorretrato juvenil, incluso en sus dibujos sobre escenas de El Quijote, se percibe ya su estilo en las miradas concentradas, en los fondos oscuros y en el ambiente inquietante que marca el pulso del artista. Todo partía, una vez más, del dibujo, siempre muy sinuoso, casi infantil en algunas obras y perseguía la explotación de las referencias estéticas. Se han señalado algunas: el Velázquez (Sevilla, 1599 - Madrid, 1660), retratista de enanos y sirvientes como modelo para sus personajes grotescos como si de un nuevo folclorismo desgarrado se tratara; el Rembrandt (Leiden, 1606 - Ámsterdam, 1669), de los insistentes autorretratos con los que justificaba Ressendi hacer los suyos ${ }^{40}$; el Valdés Leal (Sevilla, 1622 - 1690), de las Postrimerías de la Caridad para los cuadros presididos por el tono de desesperanza y locura; pero, sobre todo, el Goya de los cartones para tapices para las escenas folclóricas, incluso el de las pinturas negras que imitó cuando adquirió la finca El Zacatín y decoró sus paredes interiores ${ }^{41}$. Pero a estas destacables influencias habría que añadir otras no suficientemente destacadas aún como las de El Greco (Heraclión, 1541 - Toledo, 1614) o Zurbarán (Fuente de Cantos, 1598 - Madrid, 1664). Además, habría que encuadrar los efectos de su obra en las cercanías estéticas del rebelde pintor Francisco Cortijo (Sevilla, 1936 - Madrid, 1996) ${ }^{42}$, incluso con determinadas deudas literarias derivadas de los ambientes creados por Lino Novás Calvo (Grañas del Sor, 1903 - Nueva York, 1983) en su obra Pedro Blanco el Negrero (1973) o, incluso, con el propio Federico García Lorca (Fuente Vaqueros, 1898 - Granada, 1936), y su Romancero gitano (1928) ${ }^{43}$, como si todo ese mundo de preguerra perviviera en su pintura tamizada con el lóbrego filtro de la posguerra. Por último, habría que incidir en el modelo de Hohenleiter, quien supuso una nota de referencia para él a la hora de acometer asuntos

${ }^{39}$ Covelo López, 2000: 9 y 45, publicó algunas de sus poesías. También experimentó con la escultura como si, en un momento determinado, su nerviosa pincelada abrazara los volúmenes y saltara del lienzo para hacerse tridimensional.

${ }^{40}$ Muchos de ellos reproducidos por Covelo López, 2000: 123-127.

${ }^{41}$ Covelo López, 2000: 52. Durante la primera mitad del siglo XX, el pintor Ignacio Zuloaga (Éibar, 1870 - Madrid, 1945), actuó como auténtico revulsivo en el aprecio de la pintura del aragonés, véase Juberías Gracia, 2020.

${ }^{42}$ Este excéntrico pintor cuenta con una monografía: Raya Téllez, 2000.

${ }^{43}$ Frecuentaba los tablaos flamencos de Triana. Y allí encontró mucha autenticidad que después llevó a sus cuadros, véase Covelo López, 2000: 25. 
comunes como la ramificación de la pintura de casacas que Ressendi renombró como "goyerías" 44 .

En última instancia, en la pintura de Ressendi hay una pretensión más o menos explícita por subvertir la tradición de la historia del arte en Sevilla compilando todas las fórmulas válidas en el pasado y tamizándolas con un estilo que pertenecía por completo al artista y a sus constantes vitales -realmente relacionadas con una existencia un tanto desordenada y bohemia-, pero que podría identificarse a grandes rasgos como relacionable tanto con el expresionismo centroeuropeo de principios del novecientos como con cierto surrealismo. Todo ello resultaba ajeno a lo que le enseñaron sus maestros de la Escuela Superior de Bellas Artes ${ }^{45}$, de los que se distanció creando un espacio de moderada rebeldía estética en un momento muy crítico para la pintura española, caracterizado por la demarcación ideológica y la pobreza de ideas. Las obras que aquí se presentan por primera vez no hacen más que ratificar los valores ejercidos por Ressendi y contribuyen al mayor conocimiento y comprensión de las intenciones del artista, pero especialmente deben resaltarse las dos primeras, por aportar rasgos interesantes al catálogo del mismo y por suponer algunas de las escasas representaciones de temática religiosa practicadas por él.

El Calvario (Figura 1) (óleo sobre lienzo y firmado de 103 x $79 \mathrm{~cm}$ ), guarda cierta relación con su Descendimiento y con su Cristo yacente, como si estas piezas fueran una suerte de continuación iconográfica de aquella. De la misma manera también muestra evidentes analogías con otras versiones del drama vivido por Cristo en el Gólgota, concretamente con Crucificado rojo y Crucificado verde, aunque en estos casos figura el Redentor absolutamente en solitario y formando parte de una composición de tamaño más reducido ${ }^{46}$. No podría asegurarse, dada la extensa producción ressendiana, pero gracias a las características formales de la pintura aquí analizada es probable jugara el papel de eslabón en el marco de una serie dedicada a la vida de Cristo que estaría integrada por otros lienzos como el de la Adoración de los pastores ${ }^{47}$, de similares características ambientales y de idéntica afinidad a la hora de representar los personajes. Ressendi diseña estas pinturas con tanto detalle y dominio que casi podrían entenderse como retratos colectivos. Sobre un fondo muy oscuro, que hurta toda referencia espacial,

${ }^{44}$ A pesar de ser más cercanas a la estética de Hohenleiter que de Goya, derivó del nombre de este último, Covelo López, 2000: 15, 18 y 21. El pintor Antonio Rodríguez Almansa $(1910$ - 2010) retrató juntos a Ressendi y Hohenleiter. Se reproduce en Covelo López, 2000: 17.

45 Eso cree Valdivieso, 1986 (2002): 495. Algunos de ellos fueron Alfonso Grosso Sánchez (Sevilla, 1893 - 1983) y Eduardo Acosta Palop (Villagarcía de la Torre, 1905 - Sevi1la, 1991), según AAVV., 1979: 2.892.

${ }^{46}$ Miden 45 x 40 cm. Reproducidos por Covelo López, 2000: 183-185 y 197 y 199.

${ }^{47}$ Reproducida por Covelo López, 2000: 207. 
se proyectan las tres cruces del Calvario y se arraciman hasta diez personajes que pueden identificarse con la Virgen, las Santas Mujeres, San Juan Evangelista, San José de Arimatea y Nicodemo. La composición resulta simétrica y dividida en dos, con el eje axial que dispone la cruz de tau en la que cuelga, con cuatro clavos Cristo muerto, cuyo cuerpo es representado de forma esquemática, casi contorsionado y con tonos verdosos. Todas las miradas convergen en él con evidentes rictus de dolor que sobresalen de manera destacada por entre ropajes y tocas oscuros trazados con detalles, pero también con viva fuerza, elocuente expresión y movimiento. Ese claroscuro, igualmente, es muy evidente entre las carnaciones de los crucificados - los ladrones solo aparecen esbozados-, y el fondo negruzco. En todos los puntos esta pintura cumple con los requisitos iconográficos pertinentes, incluso a la hora de disponer la calavera de Adán al pie de la cruz. Sin embargo, antes de ejecutar una inequívoca función religiosa, prima el "esoterismo expresionista" 48 que emana de su contemplación antes que cualquier otra consideración, actuando más como recordatorio de los efectos de los sentimientos de violencia y dolor para el espectador y como recurso expresivo utilizado por el autor para mostrar su conocimiento y habilidades pictóricas.

Otra de las pinturas que aquí se aportan podría recibir el título de Los arlequines y el torero (Figura 2) (óleo sobre lienzo y firmado de $51 \times 72 \mathrm{~cm}$ ), y que podría considerarse combina los temas circenses con los taurinos. Sin ningún significado aparente, Ressendi dispone una docena de personajes grotescos en fila y en primer plano, expresando con sus rostros -encarnados como si de máscaras de carnaval se tratara-, gestos diversos -repárese en la cierta e irónica obscenidad que mantiene el torero con montera-, y variadas emociones -sorpresa, alegría, burla e ironía-, tratadas con nervio y valentía en el pincel como denominador común que amalgama toda la obra ${ }^{49}$. Algunas figuras se exponen con los brazos abiertos y vestidas con túnicas de vivos colores -como el personaje central, de amarillo y rojo-, mientras otras, en los extremos, flanquean la composición con posturas desenfadadas y actitudes mímicas. La pincelada es muy suelta, pero a pesar de utilizar esta técnica se diferencia muy bien el contorno de los personajes con el fondo nebuloso en tonos verde manzana. La sensación que el pintor transmite aquí es la del melancólico estado de ánimo de quien, como los payasos o los toreros, tienen que provocar la risa y el disfrute constante de un público eminentemente popular, dejando en sus jardines interiores el poso existencial de una vida precaria y necesitada de otros estímulos individuales e inalienables. Algo que anima a la reflexión y pretende la solidaridad y empatía del espectador.

A continuación se presentan cinco tablas de pequeño formato agrupadas en una misma serie dedicada, como fuera recurrente a lo largo del catálogo de

\footnotetext{
48 Así lo definió Hernández Díaz, 1990: s/p.

${ }^{49}$ Los lienzos de mayor analogía con este son los reproducidos por Covelo López, 2000: 137.
} 
Ressendi, a la commedia dell'arte italiana. Todas están firmadas y miden 36 x $29 \mathrm{~cm}$ cada una. En cuanto al tema, una vez más, Ressendi parte de Goya -por ejemplo de Cómicos ambulantes (Madrid, Museo Nacional del Prado, 1793) o de Duendecitos de la serie de Los caprichos, 1797-1798, para llegar a la emulación del Picasso del periodo rosa con la figuración de estos tipos populares tan cercanos al mundo del teatro ambulante y el circo multitudinario ${ }^{50}$. En cualquier caso, esta serie puede parangonarse con otras análogas de entre las que destacan las tituladas El pandero rojo o El pandero azul ${ }^{51}$. Precisamente este es el tipo de pintura más demandada por los comitentes menos comprometidos estéticamente ${ }^{52} \mathrm{y}$ que querían atesorar, como una suerte de talismán, alguna obra de Ressendi que no resultase especialmente compleja. Solía pintarlas a gran velocidad, con una notable ausencia de rasgos de precisión en las fisonomías y en los caracteres físicos, pero también con una abstracta elaboración del ambiente de fondo, presentado ahora con tintes un tanto naif ${ }^{33}$. A pesar del aparente colorido y del carácter afable, estos temas circenses o de pequeños y traviesos saltimbanquis y arlequines no transmiten felicidad alguna. Más bien están compuestos a partir de figuras tristes y abatidas ${ }^{54}$, que no interactúan entre ellas, sino que, por el contrario, interpelan al espectador con su fría mirada a la vez que encienden en él la mecha de la curiosidad acerca de las circunstancias reales que les han arrastrado a llevar ese tipo de vida errante y desagradecida ${ }^{55}$. A ello contribuye el hecho de que en la mayoría de los casos los personajes no muestren su rostro sino a través de máscaras y su silueta con la impronta que permite un colorido disfraz. En cualquier caso a Ressendi le sirven para demostrar su asombrosa técnica y su habilidad manual, dones

${ }^{50}$ No obstante su hija Paloma Vosselle desveló que Piccaso era uno de los artistas predilectos de su padre en la entrevista realizada por Alfredo Valenzuela para el diario $A B C$, 27-5-2007: 30 .

${ }^{51}$ Ambas conservadas en colecciones particulares y reproducidas por Covelo López, 2000: 134 y 135. También muy relacionables con otras reproducidas en 139, 140 y 142.

52 Medianero Hernández, 1984: 369 destaca que Ressendi fue "admirado por las clases populares" y que "en la soledad de Madrid, se dedicó a una pintura fácil y rápida destinada a la venta instantánea, muy inferior a sus verdaderas dotes como artista".

${ }^{53}$ Estas son las pequeñas tablas que recogen algunos testigos le llevaban unos veinte minutos de trabajo y que, sin embargo, podían venderse por entre 80.000 y 200.000 pesetas cada una, véase AAVV., 1979: 2.892. Habría que entender lo desorbitado de estos precios si se compara lo que ganaba un artista premiado en una exposición nacional consiguiendo el máximo galardón: en la de Bellas Artes de 1960, por ejemplo, la medalla de honor se acompañaba de 100.000 pesetas, mientras que las de primera clase para la pintura lo eran de 25.000, véase AAVV., 1960: 11.

${ }^{54}$ Así lo considera Covelo López, 2000: 213.

55 Covelo López, 2000: 213 y 222 cree que puede darse una explicación filosófica sobre la hipocresía que domina la sociedad, de "lo incierto de la apariencia y en la vaguedad y sutileza de la realidad". 
que le posibilitaban, con unas pocas pinceladas, terminar una tablita que ejecutaba sobre una silla (sentándose él enfrente) y que podía reunir, aunque fuera a pequeña escala, sus más destacados valores estéticos: maestría con la plasmación de las telas, expresividad, misterio, incentivo reflexivo y destacados recursos lumínicos. El elemento que con más determinación articula toda la serie es la repetida aparición de personajes concretos, a veces con ligeras variantes en el color.

La primera de ellas podría titularse Niños payasos con maja ataviada con sombrero de ala alta (Figura 3). En un espacio abierto, insinuado en lo pictórico con una pincelada muy suelta, se percibe un horizonte rural casi desprovisto de referencias con, tan solo, una pareja de árboles encuadrando el fondo. Junto a la sombra que se proyecta desde la izquierda se sitúan tres personajes: dos masculinos y uno femenino. Los primeros parecen de corta edad, un adolescente y un infante, vestidos con los brillantes rasos de Arlequín y ataviados con máscaras. La mujer se sitúa en el centro de los anteriores con una blusa escotada de color turquesa y una falda amarilla que sostiene las manos del más joven y escudriña al espectador casi inquisitivamente.

El segundo cuadro podría conocerse como Grupo de niños payasos con dos encapuchados (Figura 4), y muestra un conjunto de ocho personajes sobre un fondo que parece de pavimento arenoso, con el mar y la línea del horizonte en lontananza colocada bajo un cielo azulado amenazado por prominentes nubarrones grises. Los personajillos, como es tan frecuente en Ressendi en este tipo de pinturas, no interactúan entre sí, sino que parecen posar desenfadadamente para el artista, mirando con descaro al espectador o reposando con desgana, pero, no sin intención, guardando una cierta composición piramidal. La cúspide de la misma la alcanzan dos encapuchados, casi espectrales, de largos brazos, vestidos de blanco y negro y vueltos de espaldas uno contra otro. Miran al resto del grupo a través de los grandes ojos que dejan entrever los orificios de su antifaz. El personaje que aparece en el último plano, vestido de rosa, sostiene una especie de lábaro con un cartel negro en el que figura una cara de payaso sonriente-ojos, nariz y labios rojos sobre rostro blanco-, quizá como símbolo de la compañía de carnaval a la que pertenecen estos saltimbanquis.

El tercero, Grupo de niños payasos con majas (Figura 5) es muy parecido al anterior, porque quizá conforman una misma vista en continuidad: sobre semejante fondo de paisaje costero -también inserto en un ambiente bochornoso-, posan de lado cuatro niños payasos, vestidos con lustrosos rasos rojizo y blanco y custodiados por tres mujeres figuradas con trazos muy imprecisos, pero que diferencian bien sus posturas: dos de perfil y una de frente coronada por un sombrero de ala alta, en esta ocasión rojizo y atado al cuello. Detalle intrigante supone el que se aprecia en la zona izquierda: dos mujeres, juntas, llevando una de ellas un sombrero, parecen cuchichear entre ellas.

La cuarta tabla podría recibir el título de Tres payasos con maja (Figura 6) y sitúa a los cuatro personajes en el mismo espacio descrito con anterioridad. Los 
jóvenes payasos, cada uno enfundado en una brillante túnica grisácea, rojiza y azulada, respectivamente, se muestran relajados - con las manos a la espalda o sobre las caderas-, junto a una maja de rasgos oscuros que solo se percibe parcialmente al estar situada tras uno de ellos y que lleva, como ha ocurrido en algunos de los cuadritos anteriores, un sombrero de color azul adornado con un broche dorado. Casi parece que estén paralizados representando una escena de mímica ${ }^{56}$.

La quinta y última obra es la más interesante del conjunto. Saltimbanquis en acción (Figura 7), muestra un momento capital en el proceso de la actuación que están brindando dos histriones sobre una tablado que se sitúa en el centro de un espacio abierto y que está rodeado, además, por un grupo numeroso de payasos y majas con sombreros de ala alta -rojos y azules-, que, mayoritariamente, no prestan atención a lo que ocurre sobre las tablas, sino que, en ocasiones, siendo ellos espectadores reales de la escena, miran distraídamente al público que se sitúa al otro lado de los márgenes del cuadro. La complicada acrobacia -un equilibrio invertido-, en la que se encuentran enfrascados los individuos del centro de la composición la divide en dos, entre el cielo claro y diáfano y el suelo sobre el que se eleva el tablado circense y entre un grupo y otro de payasos espectadores. La indiferencia que muestran en el juego se contrapone al interés que subyace en la expresión grotesca de sus rostros al mirar más allá de la frontera del lienzo. De nuevo Ressendi hace gala de una imaginación desbordante, extraordinaria y única. Guarda esta pintura evidente relación con la última presentada en este estudio, Niños saltimbanquis jugando a la piola (óleo sobre tabla, $45 \times 37 \mathrm{~cm}$, colección particular sevillana y también firmada en el ángulo inferior derecho) (Figura 8), una delicada composición realizada con la prontitud que reservaba Ressendi para este tipo de obras, pero que, a diferencia de las que componían la serie anterior, sí parece perseguir más decididamente la inocencia y gracia infantiles. Sobre un paisaje de suelo de albero y sombreado por un par de árboles juega un grupo de chiquillos, de nuevo enfundados en sus brillantes trajes de raso de distintos colores pastel. Tres de ellos - un niño de rojo con las manos a la espalda y dos niñas con coletas-, se sitúan a la derecha y contemplan el juego de los otros tres: el del atuendo ocre está siendo saltado admirablemente por otro vestido de rosa que va a encontrarse en el suelo con el compañero que, con traje claro, ha caído de bruces un momento antes. De nuevo se produce aquí una unión de contrarios, tan habitual en la pintura de Ressendi: a pesar del movimiento que implica el juego ejecutado por los personajes, la composición parece bastante estática, sobre todo por la parálisis que aqueja a los tres espectadores del salto. Igualmente, aunque uno de los niños se ha caído, el resto no muestra reacción o sorpresa alguna, ni siquiera una irónica sonrisa en sus semblantes. Todo parece presidido por un inquietante ambiente metafísico, como de formas cuyo hondo significado no es el

${ }^{56}$ Guarda esta pintura absoluta analogía con los Tres niños payasos que salió a la venta en Ansorena en marzo de 2020. 
corriente o primigenio. Aunque la representación de saltimbanquis y niños payasos fue idónea para la atropellada pintura de Ressendi -y sus consecuentes y beneficiosas ventas-, no estuvo exenta de resultar una aportación que, pasados los primeros agobios y presiones de los inicios de su carrera o las responsabilidades y compromisos de su primera etapa en Madrid, resumía en las últimas décadas de su trayectoria -los sesenta y los setenta-, mucho de la desesperanza y sombría decadencia de las pinturas que le habían hecho gozar de fama y prestigio.

Las consideraciones finales de este estudio pretenden incidir en la fortuna artística que cosechó Ressendi tras su desaparición. Efectivamente, el profesor Valdivieso cerró con él su libro sobre pintura sevillana ${ }^{57}$ en 1986 y tan solo habiendo transcurrido una década desde su muerte se organizaron dos importantes exposiciones que extendieron el conocimiento de su obra: la del Ateneo y la del Ayutamiento de Sevilla ${ }^{58}$. Tres años más tarde tuvo lugar la de la Caja de Ahorros San Fernando $^{59}$. Con criterios distintos se montaron las de dibujos en Alcalá de Guadaira ${ }^{60}$ y la de la Fundación Municipal de Cultura de Sanlúcar ${ }^{61}$ y otra más en la localidad alcalareña ${ }^{62}$. Por los mismos años volvió a suscitar el interés de algunos investigadores, como De la Banda y Vargas o Fernández Lacomba ${ }^{63}$, pero fue la decisiva monografía de Covelo López la que reprodujo el mayor conjunto de pinturas debidas a su mano y ofreció algunas líneas temporales y explicaciones para la comprensión de las mismas ${ }^{64}$.

57 Valdivieso, 1986 (2002): 495-497.

${ }^{58}$ Celebrada en el Alcázar y comisariada por un seguidor de la estética de Ressendi, el pintor Fernando Ruiz Monedero (Sevilla, 1953), véase ABC de Sevilla, 16-5-1987: 57. Se centraba en su obra conservada en colecciones particulares.

${ }^{59}$ Celebrada en octubre de 1990, el catálogo es el de AAVV., 1990.

${ }^{60}$ Se celebró en marzo de 1994.

${ }^{61}$ Tuvo lugar en 1996. En esta localidad había expuesto en sus primeros años, debido a que era lugar de trabajo de su padre, véase Covelo López, 2000: 22. En aquella población trabajó mucho gracias a los encargos de uno de sus vecinos más sobresalientes, el boticario Rafael Reig de Argüeso, que actuó como mecenas de Ressendi durante bastantes años. Para conocer más sobre este destacado personaje sanluqueño, véase Fernández Navamuel, 1998: 63-69.

${ }_{62}$ Ressendi en Alcalá de Guadaira fue comisariada en 2007 con un interesante texto de Luis Romera Ojeda (1932-1999), pintor local que frecuentó mucho a Ressendi durante su etapa en ese municipio sevillano.

${ }^{63}$ De la Banda, 1994: 423. Fernández Lacomba, 1995.

${ }^{64}$ Covelo López, 2000. La difusión de su obra posibilitó que el afamado guitarrista Manolo Sanlúcar (Sanlúcar de Barrameda, 1943), se inspirara en ella para componer La voz del color, una pieza estrenada en la Bienal de Flamenco de 2008, véase $A B C$ de Sevilla, 15-7-2008: 65. Félix Machuca le dedicó un florido artículo titulado "Baldomero Romero Ressendi: la vida loca" en $A B C$ de Sevilla, 21-9-2019: 24, basándose en el testimonio de algunos de los anticuarios que lo trataron. Ese fue el nicho en el que encontró mayor acomodo la pintura de Ressendi tras su muerte, ya que, como indicó Covelo López, 2000: 
Con respecto a su continuidad estilística en la pintura sevillana, parece que no tuvo seguidores claros y que cerró toda una etapa en el seno de la misma ${ }^{65}$. Los pintores que se activaron después, aunque formados en ella, ya no tenían nada que ver con el academicismo hispalense y bajo diversos nombres -Grupo del 49, Joven Escuela Sevillana, Libélula, Grupo Sevillano-, probaron otras soluciones y, mayoritariamente, perdieron la referencia local. En eso se diferenciaron enormemente de Ressendi, porque aunque siguió planteamientos tradicionales, muy asentados en el mercado artístico local, restó amabilidad a la factura de los mismos y sumó extravagancia a las soluciones de los grandes maestros que siempre tuvo presentes -entre los que sobresalió Valdés Leal-, para abarrocarlas sobremanera con la intención de explotar sus recursos expresivos y procurar, así, un "esoterismo expresionista" ${ }^{66}$ de indudable calidad que, aunque contribuyó en un primer momento a fijar su fama y gloria como pintor, hoy sigue siendo bastante desconocido al ocupar un plano secundario en la historia del arte contemporáneo español ${ }^{67}$.

Fecha de recepción: 27 de octubre de 2020.

Fecha de aceptación: 2 de mayo de 2021.

55: "En lugar de los destellos de las galerías, el ambiente de Ressendi es el opaco mundo de los anticuarios".

${ }^{65} \mathrm{Su}$ coetáneo Manuel Monedero (Sevilla, 1925 - 2002), podría considerarse su casi único y más claro imitador. Conoció a Ressendi a través del escándalo de Las tentaciones de San Jerónimo en 1946 y poco después ya frecuentaba el estudio de la referencia de Ressendi, Hohenleiter. Él mismo confesó estas influencias: "Romero Ressendi y Hohenleiter influyeron en mí para pintar", véase Fernando Gelán, El Correo de Andalucía, 29-10-1965.

${ }^{66}$ Expresión de Hernández Díaz, 1990: s/p. Carmen Íñiguez Berbeira prefirió clasificarlo como "l'enfant terrible de la pintura andaluza", véase Íñiguez Berbeira: 31.

${ }^{67}$ Luis Gordillo (Sevilla, 1934), pintor tan solo algunos años más joven que Ressendi ha devenido en figura indiscutible en el ámbito nacional. 


\section{BIBLIOGRAFÍA}

AAVV. (1960): Catálogo de la Exposición Nacional de Bellas Artes. Barcelona: Ministerio de Educación Nacional, Dirección General de Bellas Artes.

(1979): "Romero Ressendi, Baldomero". En: Gran Enciclopedia de Andalucía. Sevilla: Tierras del Sur, t. 7, p. 2.892. (1990): R. Ressendi. Sevilla: Caja San Fernando.

Campoy, Antonio M. (1977): "El pudor del trabajo". En: AAVV.: Florentino Pérez-Embid: Homenaje a la amistad. Barcelona: Editorial Planeta, pp. 86-87.

(1990): "Aproximación a Romero Ressendi". En: AA.VV.: R. Ressendi. Sevilla: Caja San Fernando, s/p.

Covelo López, Juan Manuel (2000): Baldomero Romero Ressendi. Sevilla: Guadalquivir Ediciones.

De la Banda y Vargas, Antonio (1994): De la Ilustración a nuestros días. Sevilla: Gever.

Fernández Lacomba, Juan (1995): "Romero Ressendi”. En: Siglo que viene. Revista de cultura, 23, pp. 18-24.

Fernández Navamuel, Jesús (1998): León de Argüeso. Una voluntad de hierro. Arija.

González Gómez, Juan Miguel (1998): "Perfil universitario del Doctor Don José Hernández Díaz". En: Laboratorio de arte, 11, pp. 13-26.

Hernández Díaz, José (1990): "Glosario del pintor Romero Ressendi". En: AA.VV.: $R$. Ressendi. Sevilla: Caja San Fernando, s/p.

Íñiguez Berbeira, Carmen (2018): "Los quitasoles. Baldomero Romero Ressendi". En: Ariza Galán, Rafael (coord.): Catálogo de la colección de bienes muebles. Fundación Casa de Medina Sidonia. Sevilla: Consejería de Fomento y Vivienda de la Junta de Andalucía y Diputación de Cádiz, pp. 30-36.

Juberías Gracia, Guillermo (2020): "Ignacio Zuloaga (1870-1945) y su rol en el coleccionismo de obras de Goya”. En: Holguera Cabrera, Antonio, Prieto Ustio, Ester y Uriondo Lozano, María (coords.): Coleccionismo, mecenazgo y mercado artístico: orbis terrarum. Sevilla: Universidad de Sevilla, pp. 274288.

Medianero Hernández, José $M^{a}$ (1984): "El arte desde el siglo XIII hasta nuestros días”. En: AA.VV.: Sevilla y su provincia. Sevilla: Ediciones Gever, pp. 197-375.

Raya Téllez, José (2000): El pintor Francisco Cortijo, 1936-1996. Sevilla: Universidad de Sevilla.

Romero Contreras, Elisa (1990): "Bibliografía”. En: AA.VV.: R. Ressendi. Sevilla: Caja San Fernando, s/p.

Valdivieso, Enrique (1986-2002): Historia de la pintura sevillana, siglos XIII al $X X$. Sevilla: Guadalquivir Ediciones. 


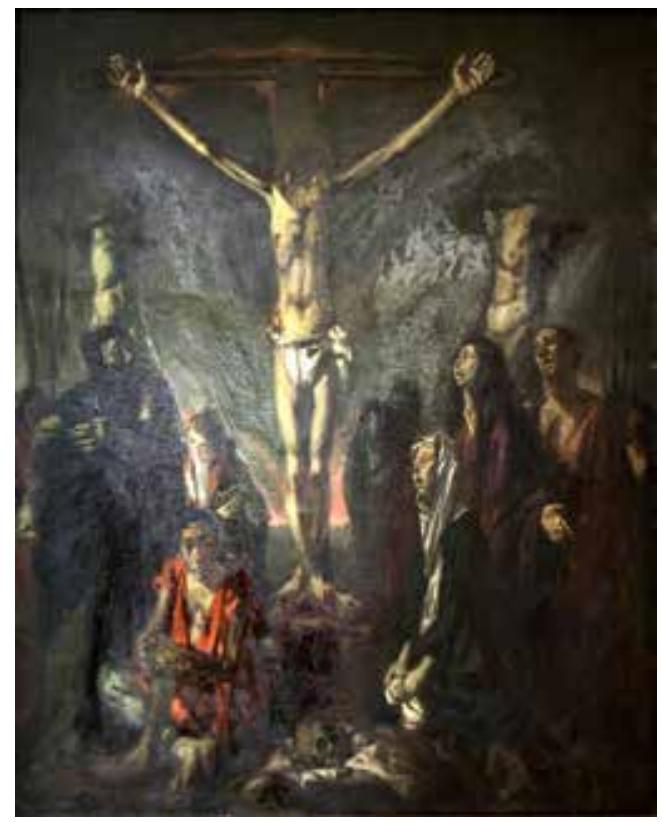

Fig. 1. Baldomero Romero Ressendi. El Calvario. Sevilla. Colección particular.

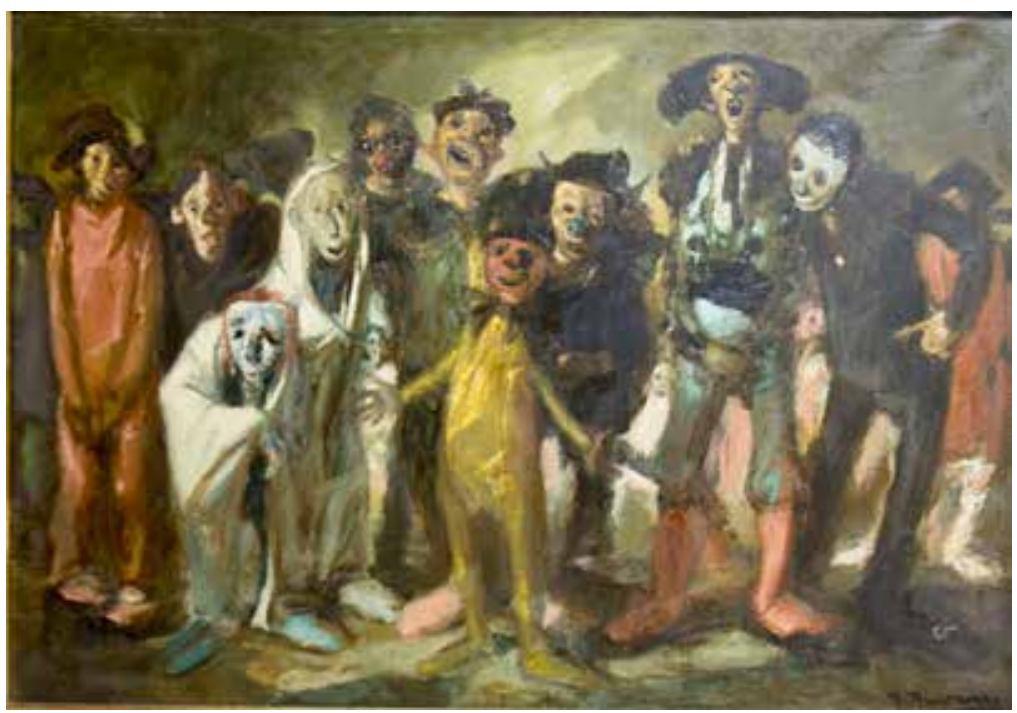

Fig. 2. Baldomero Romero Ressendi. Los arlequines y el torero. Sevilla. Colección particular. 


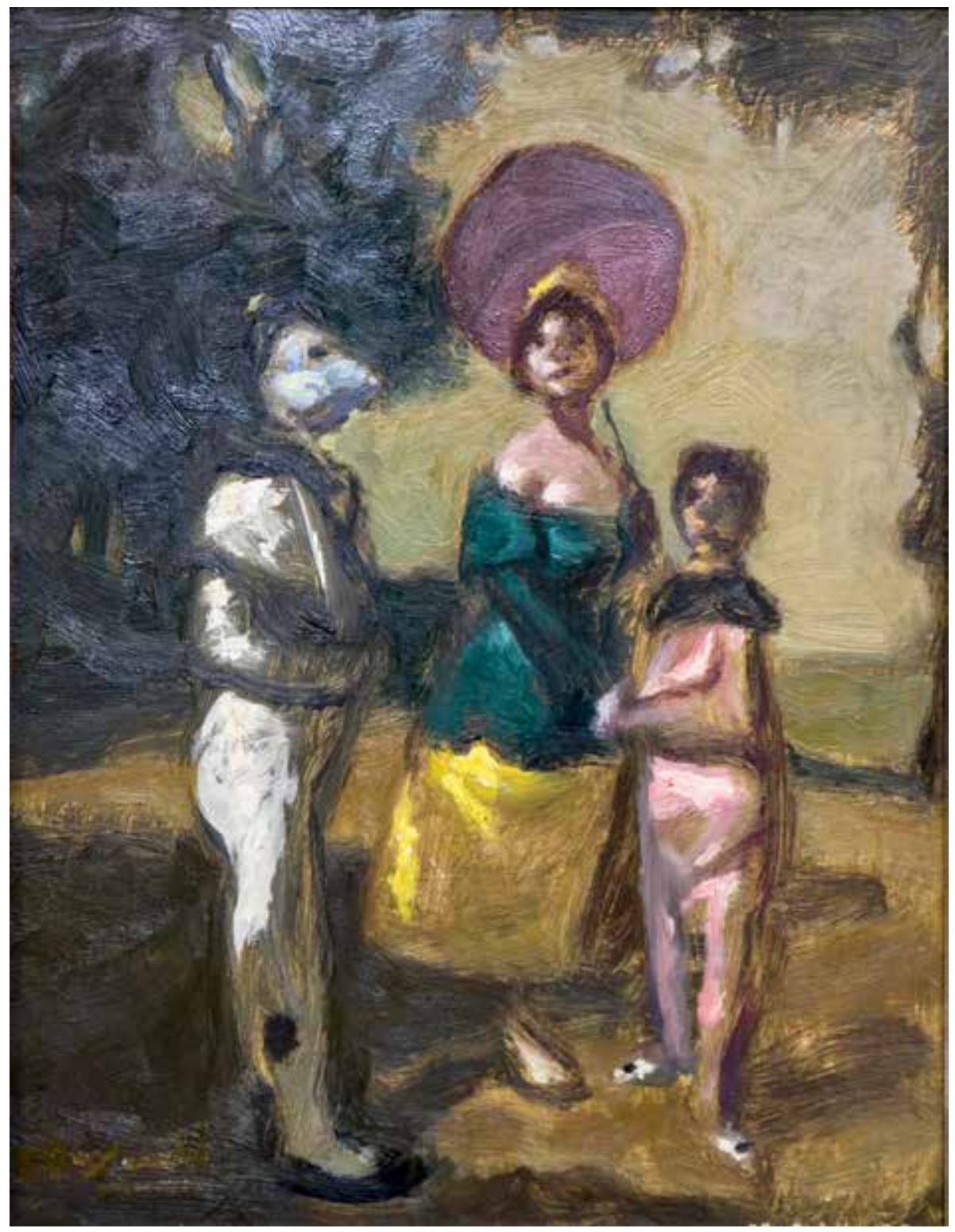

Fig. 3. Baldomero Romero Ressendi. Niños payasos con maja ataviada con sombrero de ala alta. Sevilla. Colección particular. 


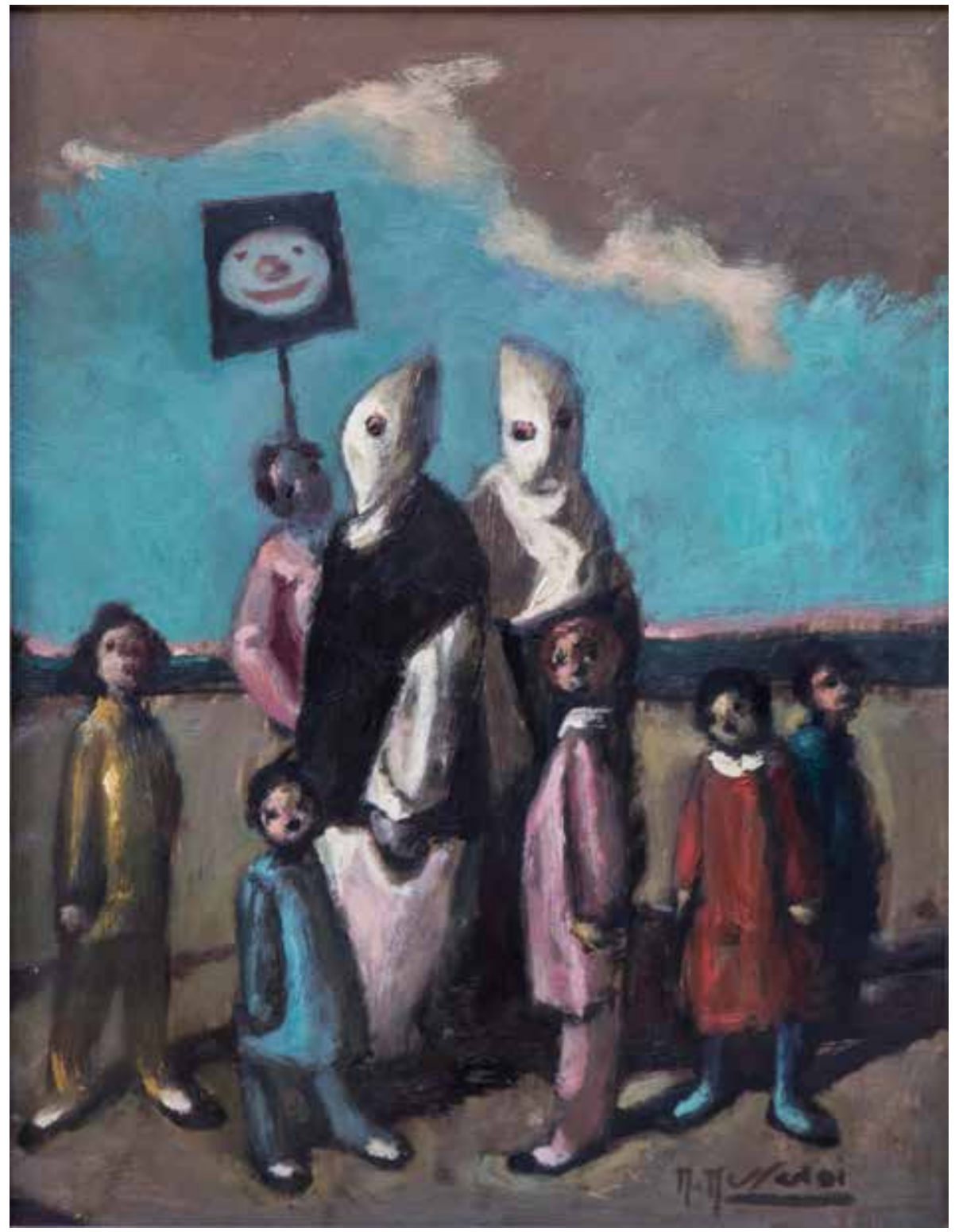

Fig. 4. Baldomero Romero Ressendi. Grupo de niños payasos con dos encapuchados. Sevilla. Colección particular. 


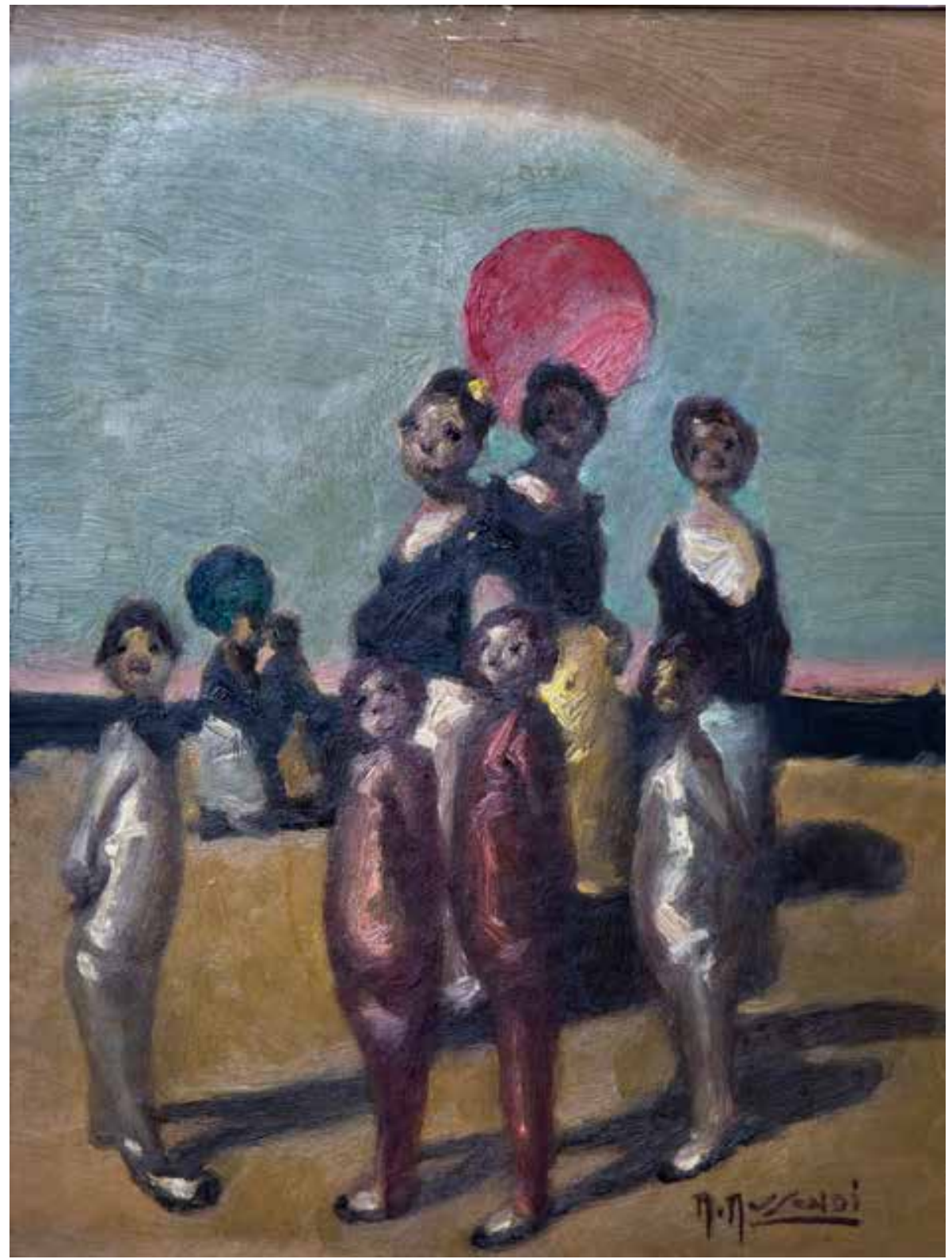

Fig. 5. Baldomero Romero Ressendi. Grupo de niños payasos con majas. Sevilla. Colección particular. 


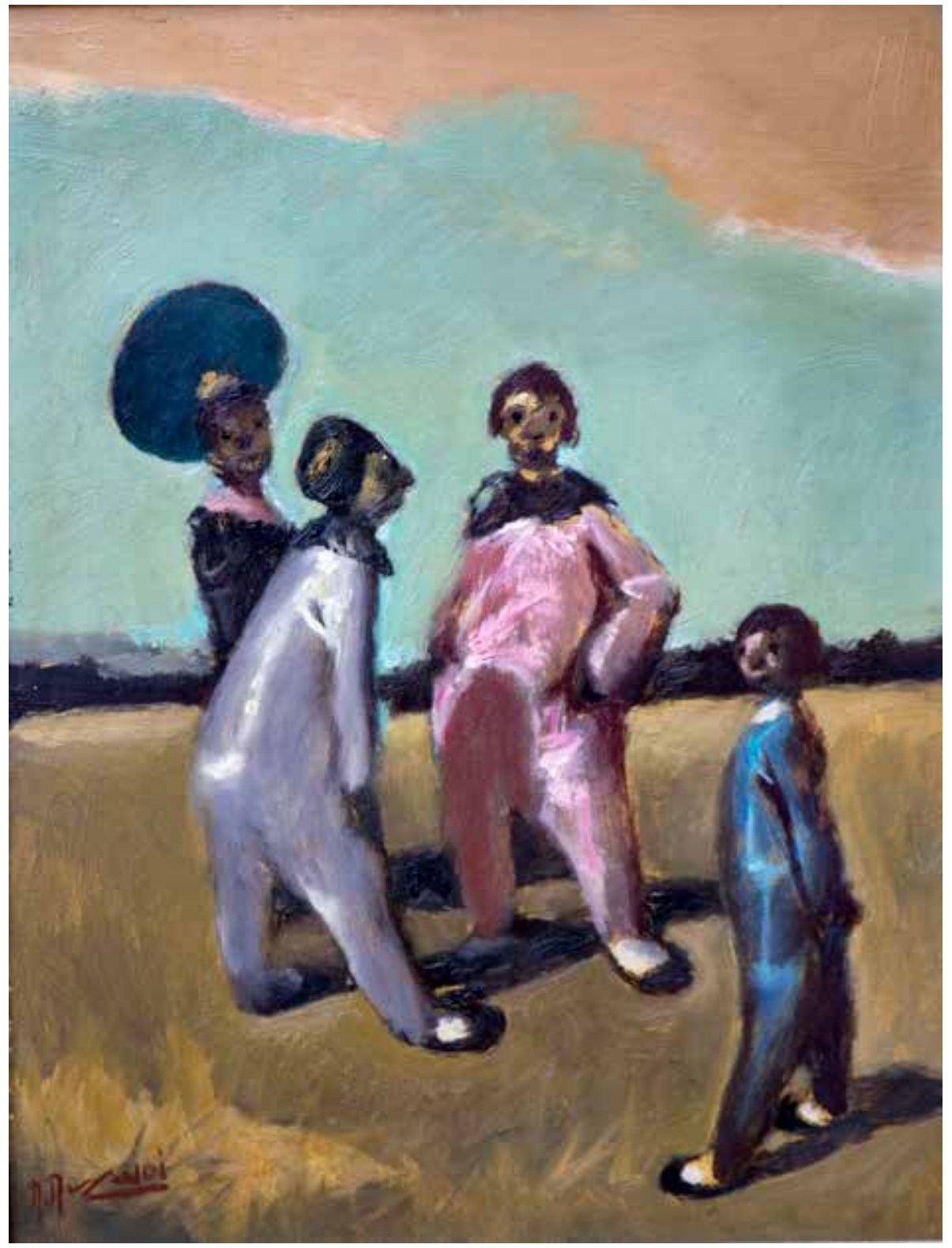

Fig. 6. Baldomero Romero Ressendi. Tres payasos con maja. Sevilla. Colección particular. 


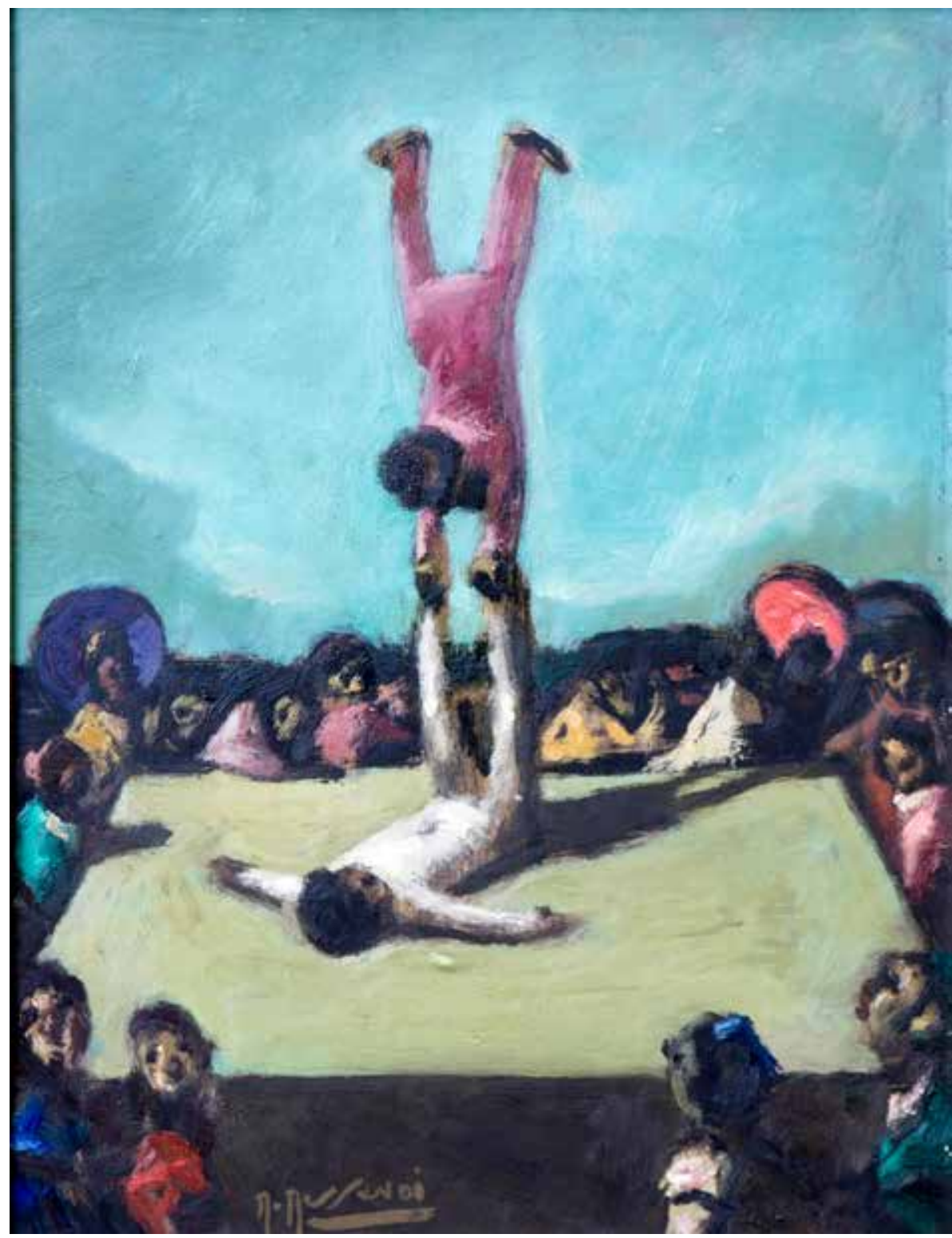

Fig. 7. Baldomero Romero Ressendi. Saltimbanquis en acción. Sevilla. Colección particular. 


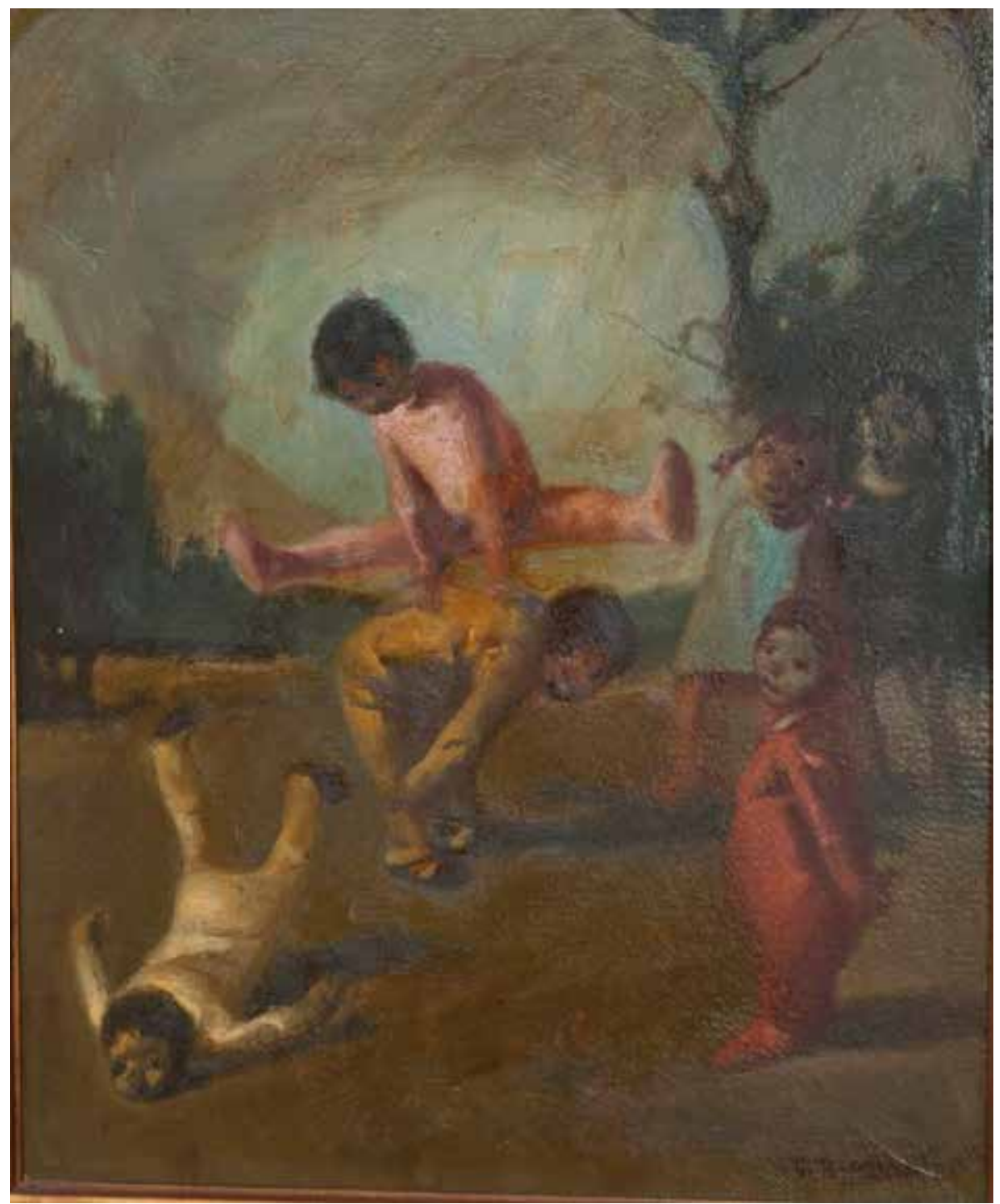

Fig. 8. Baldomero Romero Ressendi. Niños saltimbanquis jugando a la piola. Sevilla. Colección particular. 